\title{
Risk factors associated with potential cardiovascular and cerebrovascular adverse events in elderly individuals assisted at secondary level
}

\author{
(iD) Henrique Souza Barros de Oliveira ${ }^{1}$ \\ (iD) Ana Claudia Michels ${ }^{1}$ \\ (iD) Maysa Nahime \\ (iDLorena de Melo Caetano ${ }^{2}$ \\ (iD) Maria Luiza Galoro Corradi, ${ }^{12}$
}

1. Faculdade de Medicina, Centro Universitário São Camilo (Cusc), São Paulo, SP, Brasil. 2. Departamento de Clínica Médica, Hospital Geral de Carapicuíba (HGC), Carapicuíba, SP, Brasil.

http://dx.doi.org/10.1590/1806-9282.66.8.1087

\section{SUMMARY}

OBJECTIVE: To identify the use of Potentially Inappropriate Medications with imminent risk of Cardiovascular and Cerebrovascular Adverse Events (PIM-CCVAE), in addition to the factors associated with a group of elderly individuals undergoing therapeutic care in a Brazilian public service.

METHODS: A cross-sectional retrospective study conducted at a secondary level service located in Carapicuíba, SP, Brasil. Only elderly individuals ( $\geq 60$ years) who were treated in one of the outpatient departments were included. The use of PIM-CCVAE was defined based on the PIM-CCVAEs list. In this research, we used descriptive statistics and logistic regression to identify and track possible predictors of MPI use. All statistical analyses were performed using Stata software version 15.1 (Stata Corporation).

RESULTS: The sample included 233 elderly individuals, with a mean age of $74.9( \pm 9.4)$ years. Of these, $74.2 \%$ used at least one PIM-CCVAE, with an average daily intake of $1.3( \pm 1)$ PIM/elderly. The presence of comorbidities, diseases of the circulatory system, polypharmacy, and low to moderate scores in morbidity and mortality were important factors associated with an increased odds ratio for the consumption of PIM-CCVAE. It is also emphasized that the presence of neurological symptoms proved to be a protective factor for this outcome.

CONCLUSION: Given the clinical severity and imminent risk of CCVAE in the researched group, preventive measures should be instituted to minimize health problems related to medication in the public network.

KEYWORDS: Aged. Treatment outcome. latrogenic disease. Potentially inappropriate medication list. Drug-related side effects and adverse reactions. Cardiovascular system.

\section{INTRODUCTION}

Cardiovascular and cerebrovascular events are, in large part, responsible for the high rates of mortality worldwide, especially in the oldest population groups'. Due to the changes caused by the aging process, the elderly are more susceptible to acute and subacute events related to underlying causes and iatrogenic outcomes, such as: drug interactions; adverse events; use of medications that aggravate the underlying condition and/or use of drugs without scientific evidence (Potentially Inappropriate Medications - PIM) $)^{2-5}$. 
Given this scenario, Aguiar et al. ${ }^{6}$ developed a list of PIM with a potential risk for cardiovascular and cerebrovascular adverse events in elderly patients based on a systematic review that included 24 lists of PIM indexed into the literature and implemented in various places worldwide. Despite this recent indexation, there is still little evidence related to the use of PIM and the potential risk of cardiovascular events in elderly patients, especially in the oldest populations of South America.

Given that, the objective of this research was to identify the use of PIM with a potential risk of adverse cardiovascular and cerebrovascular events (ADE-CC), in addition to its associated factors in a group of elderly patients undergoing therapeutic follow-up in a public service located in the city of Carapicuíba, SP, Brasil.

\section{METHODS}

\section{Research design and scope}

A cross-sectional and retrospective study conducted with a group of elderly individuals assisted by a medical team with clinical subspecialties in a secondary health care service, located in the city of Carapicuíba, São Paulo, SP, Brasil.

\section{Inclusion and exclusion criteria}

The following criteria were considered for the inclusion of patients in this study: (i) age $\geq 60$ years; (ii) both sexes; (iii) have, at least, one consultation with the staff of the internal medicine clinic and subspecialties (geriatrics, cardiology, pulmonology, nephrology, rheumatology; neurology; general practitioners; hematology; dermatology); (iv) and undergoing a drug regimen (at least, one drug).

Exclusion was considered for those who met the following criteria: (i) absence of a description of the medications in use in electronic records, regardless of the reason.

\section{Analysis variables}

For the characterization, we evaluated: age; sex; medical specialties under follow-up or that were previously followed-up by this service; time under outpatient care in this service; the presence of morbidities diagnosed and under treatment; stratification of the clinical severity by the Charlson Comorbidity Index (CCI $)^{7}$, Charlson Age-Comorbidity Index (CACI) online $^{8}$ and Functional Comorbidity Index (FCI $)^{9}$; the chief complaint of the most recent consultation; use of continuous medication; the presence of polypharmacy, determined as the continuous use of $\geq 5$ medications; ${ }^{3}$ use of psychotropic drugs and presence of PIM wit a potential risk of ADE-CC, based on the PIMCCVAEs list ${ }^{6}$.

\section{METHODS}

Based on a list for patient control containing previously scheduled consultations, we conducted a systematic search of electronic records considering the criteria described above for eligibility of the sample. The researchers conducted filled out the survey forms and, subsequently, this information was transferred to an exclusive database for tabulation, stratification, tracking, and storage of the data. All the data collected were subjected to revision and codification, and when inconsistency was detected, it was corrected based on the electronic medical record.

All medicines with trade names were identified using the dictionary of pharmaceutical specialties and classified according to the Anatomical Therapeutic Chemical Code (ATC) index on-line (version 2019), which is recommended worldwide by the World Health Organization Collaborating Center for Drug Statistics Methodology, Norwegian Institute of Public Health. This codification is recognized as an international standard for the development of pharmacological research and divides drugs into five levels. For this study, we adopted the $1^{\text {st }}$ level classification (organ or system on which the medicine acts) ${ }^{10}$.

The application of the PIM-CCVAEs list for screening PIM with a potential risk of causing: cerebrovascular accident; transitory ischemic accident; acute myocardial infarction; heart failure; systemic arterial hypertension; orthostatic hypotension or postural hypotension, bradycardia; prolongation of the QT interval, and arrhythmias in the elderly was employed, including for screening of factors associated with this outcome ${ }^{6}$.

\section{Statistical analysis}

We carried out a descriptive analysis of the data obtained, which included a description of the population studied and the distributions of absolute and relative frequency of the categorical variables and measures of central tendency and dispersion of quantitative variables. The screening of factors was done between the variables described above and the potential iatrogenic outcome - use of PIM and risk of 
ADE-CC - through the use of multiple logistic regression per Stepwise Forward model.

For the logistic regression, we calculated the respective odds ratios (OR), confidence interval of 95\% $(95 \% \mathrm{CI})$, and $p$-value of the variables included in this model. We selected for this model only the variables with a $p$-value $<0.20$ and that remained in the final model, upon adjustment and statistical significance. All tests were carried out using the Stata software version 15.1 (Stata Corporation, College Station, United States), and we considered a level of statistical significance of $5 \%$ for all tests.

\section{RESULTS}

We included in the sample 233 electronic records of elderly patients undergoing therapeutic regimens, whose mean age was $74.9( \pm 9.4)$ years. Of these, there was a predominance of males $(50.2 \%)$, with three or more chronic comorbidities (86.6\%), mostly circulatory diseases $(73.8 \%)$, with an estimated moderate relative risk of death between the indexes measured (CCI: $2.5 \pm 2.3$ - estimated 10-year survival: $77 \%$; CACI: $5.6 \pm 2.6$ - estimated relative risk of death: 6.38 and $95 \%$ confidence interval: 3.07-12.2; FCI: 2.1 \pm 1.2 ) (Figure 1); with complaints, mainly, of symptoms related to the respiratory (33\%) and neurological (19.3\%) systems, undergoing medical assistance from an average of 2.5 $( \pm 1.2)$ prescribing professionals, and for an average period of $3( \pm 2.8)$ years under clinical assistance in this service.

From the systematic review of the medical records, we obtained a total of 1,548 medications prescribed during medical assistance, with the presence of polypharmacy in $72.5 \%$ of the sample and an average of 6.6 $( \pm 3.1)$ drugs per elderly individual. In addition, 39.4\% made use of psychotropic substances continuously and concomitant to other medicines.

Based on the ATC classification, we noticed a prevalence of medicines prescribed for the cardiovascular system, followed by the digestive system and metabolism, blood and hematopoietic organs, and respiratory system (Table 1). The main medicines prescribed to this group were acetylsalicylic acid - ASS (7.7\%), simvastatin $(7.4 \%)$, losartan (5.6\%), omeprazole (4.6\%) and carvedilol (4.3\%).

We identified that $74.2 \%$ of elderly respondents made use of, at least, one PIM with a potential risk of ADE-CC, reaching an average of daily consumption equal to $1.3( \pm 1)$ PIM/elderly. Of these, we must
FIGURE 1. USE OF THE CHARLSON COMORBIDITY INDEX (CCI), CHARLSON AGE-COMORBIDITY INDEX (CACI), AND FUNCTIONAL COMORBIDITY INDEX (FCI) TO ANALYZE THE PREVALENCE OF COMORBIDITIES IN ELDERLY INDIVIDUALS UNDERGOING OUTPATIENT CARE. CARAPICUÍBA, SP, BRASIL, 2016-2017.
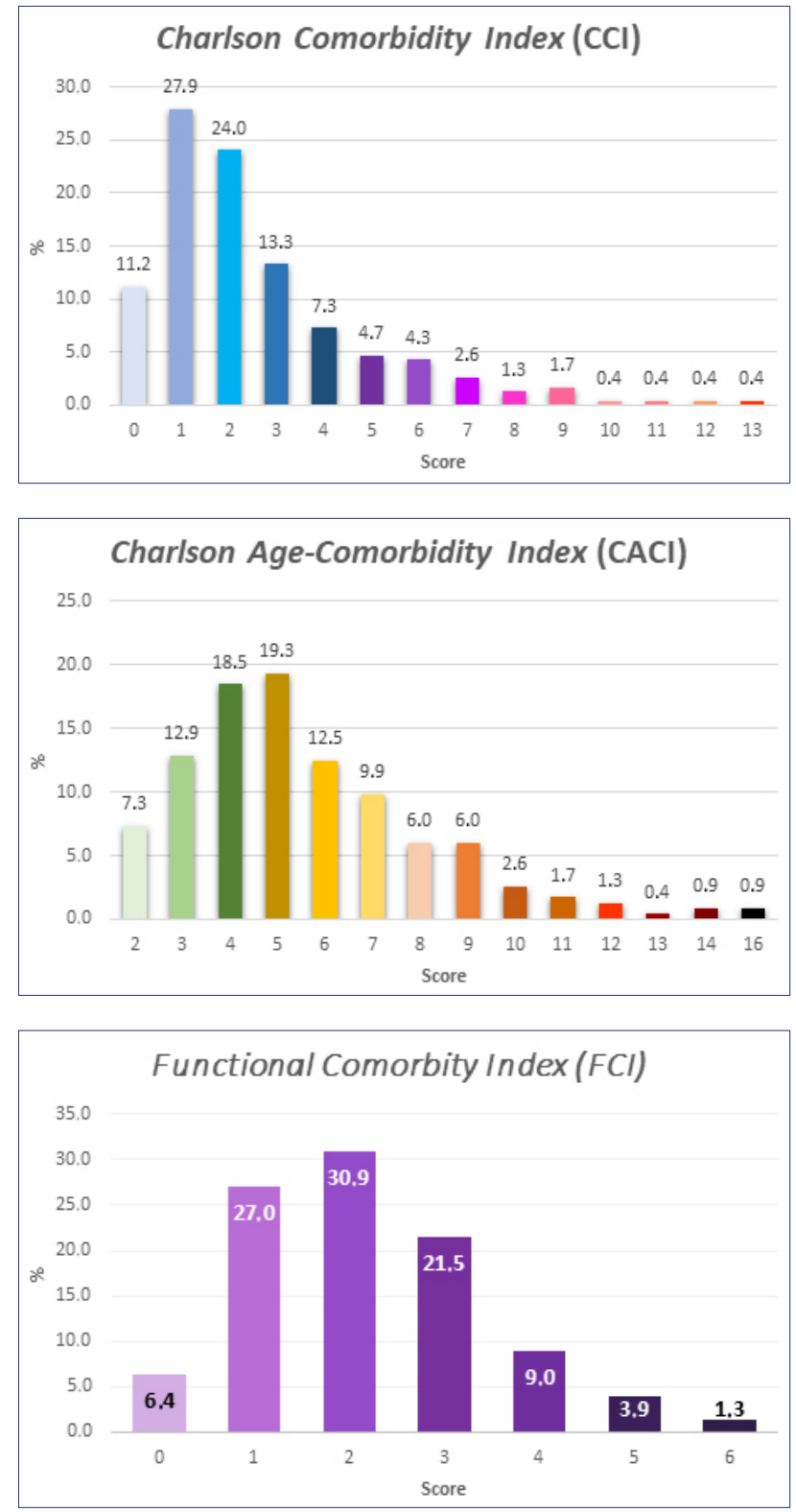

highlight that $78.5 \%$ made use of medications with an imminent risk of ADE-CC considered of lesser severity. Systemic arterial hypertension (39.5\%) and the prolongation of the QT interval (21.2\%) were the main and potential adverse events of lower severity (Table 2). While the potential risk of heart failure/exacerbation (21.2\%) was the most prevalent among the potential adverse events of greater severity.

Regarding the analyses of the association between potential ADE-CC and the other variables, we found that the presence of comorbidities equal to or greater than three was the variable most strongly associated 
with them. We further noted that with every one-point increase on the scales of morbidity and mortality, the odds ratio for the possible iatrogenic outcome analyzed was increased significantly. Like it is the case with polypharmacy, the presence of a disease of the circulatory system was also strongly associated with increased risk for PIM with a potential risk of ADE-CC.

It is necessary to highlight that the presence of neurological symptoms was a protective factor of up to $63 \%$ in comparison with the others for the outcome

TABLE 1. ANATOMICAL CLASSIFICATION OF THE MAIN DRUGS USED BY ELDERLY INDIVIDUALS ASSISTED IN A TEACHING OUTPATIENT CLINIC, ACCORDING TO THE ANATOMICAL THERAPEUTIC CHEMICAL (ATC). CARAPICUÍBA, SP, BRASIL, 2016-2017.

\begin{tabular}{l|l|l} 
Code & Anatomical Classification & $\mathrm{n}(\%)$ \\
\hline A & Digestive System and Metabolism & $242(15.6)$ \\
\hline B & Blood and Hematopoietic Organs & $189(12.2)$ \\
\hline C & Cardiovascular System & $672(43.4)$ \\
\hline D & Dermatological & $01(0.06)$ \\
\hline G & Genitourinary System and Sex Hormones & $09(0.5)$ \\
\hline H & $\begin{array}{l}\text { Hormonal Preparations for Systemic Use, } \\
\text { Excluding Sex Hormones and Insulin }\end{array}$ & $34(2.1)$ \\
\hline J & General Anti-Infectives for Systemic Use & $06(0.3)$ \\
\hline L & $\begin{array}{l}\text { Antineoplastic and Immunomodulating } \\
\text { Agents }\end{array}$ & $02(0.1)$ \\
\hline C & Musculoskeletal System & $53(3.4)$ \\
\hline N & Central Nervous System & $166(10.7)$ \\
\hline P & Antiparasitic Products & $0(0)$ \\
\hline R & Respiratory System & $169(10.9)$ \\
\hline S & Sensory Organs & $03(0.1)$ \\
\hline V & Various or Others & $02(0.1)$ \\
\hline Total & & $1548(100)$ \\
\hline
\end{tabular}

TABLE 2. PREVALENCE OF MAJOR AND POTENTIAL CARDIOVASCULAR AND CEREBROVASCULAR ADVERSE EVENTS (ADE-CC) SECONDARY TO THE USE OF POTENTIALLY INAPPROPRIATE MEDICATIONS FOUND IN THE ELDERLY. CARAPICUÍBA, SP, BRASIL, 2016-2017.

\begin{tabular}{|c|c|}
\hline Potential Adverse Events & $\mathrm{n}(\%)$ \\
\hline \multicolumn{2}{|c|}{ Cardiovascular and cerebrovascular adverse events (Major) - (21.46\%) } \\
\hline Cerebrovascular Accident & $11(03.5)$ \\
\hline Acute Myocardial Infarction & $09(02.9)$ \\
\hline Sudden Cardiac Death & $06(01.9)$ \\
\hline Heart Failure (Exacerbation of Heart Failure) & $65(21.2)$ \\
\hline \multicolumn{2}{|c|}{ Cardiovascular adverse events (Minor) - (78.53\%) } \\
\hline Systemic Arterial Hypertension & $121(39.5)$ \\
\hline Heart Block & $13(04.2)$ \\
\hline Postural and Orthostatic Hypotension & $60(19.6)$ \\
\hline Heart Arrhythmia & $50(16.3)$ \\
\hline Bradycardia & $24(07.8)$ \\
\hline Prolonged QT interval & $65(21.2)$ \\
\hline
\end{tabular}

analyzed. Table 3 shows the main findings of the logistic regression of the group researched.

\section{DISCUSSION}

In addition to being the main cause of mortality worldwide, CADs are also an important cause of morbidity in elderly individuals. As a result of the characterization of the morbidity profile of the group studied, we observed that the prevalence of chronic

TABLE 3. STEPWISE FORWARD LOGISTIC REGRESSION ANALYSIS FOR SCREENING FACTORS ASSOCIATED WITH THE USE OF POTENTIALLY INAPPROPRIATE MEDICATIONS (PIM) AND THE POTENTIAL RISK OF ADVERSE CARDIOVASCULAR AND CEREBROVASCULAR EVENTS IN ELDERLY INDIVIDUALS UNDER THERAPEUTIC REGIMEN. CARAPICUÍBA, SP, BRASIL, 2016-2017.

\begin{tabular}{|c|c|c|c|c|}
\hline \multirow[t]{2}{*}{ Variables } & \multicolumn{2}{|c|}{ Univariate Analysis } & \multicolumn{2}{|c|}{ Multivariate Analysis } \\
\hline & OR $(95 \% \mathrm{Cl})$ & $\mathrm{p}$ & OR $(95 \% \mathrm{Cl})$ & $\mathrm{p}$ \\
\hline \multicolumn{5}{|l|}{ Sex } \\
\hline Male & 1 & & 1 & \\
\hline Female & $1.32(0.73-2.39)$ & 0.349 & $1.13(0.5-2.4)$ & 0.757 \\
\hline \multicolumn{5}{|l|}{ Age } \\
\hline $60-69$ & 1 & & 1 & \\
\hline $70-70$ & $1.46(0.70-3.01)$ & 0.311 & $1.19(0.46-3.11)$ & 0.721 \\
\hline$\geq 80$ & $1.31(0.66-2.64)$ & 0.44 & $0.71(0.29-1.75)$ & 0.455 \\
\hline \multicolumn{5}{|c|}{ Comorbidities } \\
\hline$<3$ & 1 & & & \\
\hline$\geq 3$ & $10.55(4.5-24.7)$ & $<0.001$ & & \\
\hline \multicolumn{5}{|l|}{ DCS: } \\
\hline No & 1 & & 1 & \\
\hline Yes & $5.67(2.98-10.8)$ & $<0.001$ & $3.77(1.65-8.58)$ & 0.002 \\
\hline \multicolumn{5}{|c|}{ Morbidity and Mortality } \\
\hline $\mathrm{CCl}$ & $1.44(1.18-1.76)$ & $<0.001$ & & \\
\hline $\mathrm{CACl}$ & $1.29(1.11-1.49)$ & 0.001 & & \\
\hline $\mathrm{FCl}$ & $2.38(1.71-3.31)$ & $<0.001$ & & \\
\hline
\end{tabular}

Respiratory symptoms

\begin{tabular}{l|l|l|l|l}
\hline No & 1 & & & \\
\hline Yes & $0.73(0.40-1.35)$ & 0.313 & & \\
\hline
\end{tabular}

Neurological symptoms

\begin{tabular}{l|l|l|l|l}
\hline No & 1 & & 1 & \\
\hline Yes & $0.82(0.40-1.69)$ & 0.592 & $0.37(0.14-0.96)$ & 0.041 \\
\hline Polypharmacy & 1 & & 1 & \\
\hline No & $11.0(5.58-21.7)$ & $<0.001$ & $6.56(2.84-15.1)$ & $<0.001$ \\
\hline Yes &
\end{tabular}

Use of psychotropics

\begin{tabular}{c|l|l|l|l}
\hline No & 1 & & & \\
\hline Yes & $1.43(0.77-2.64)$ & 0.259 & & \\
\hline $\begin{array}{l}\text { Period under medi- } \\
\text { cal assistance }\end{array}$ & $1.01(0.89-1.14)$ & 0.903 & & \\
\hline
\end{tabular}

OR: Odds Ratio (estimated by Stepwise Forward logistic regression); $95 \mathrm{Cl} \%$ : Confidence interval of 95\%; DCS: Diseases of the circulatory system; CCl: Charlson Comorbidity Index; CACl: Charlson Age-Comorbidity Index; FCl: Functional Comorbidity Index. 
degenerative diseases, predominantly $\mathrm{CAD}$, matches the data given in the literature ${ }^{1,5,11,12}$. We further noted that considering the index of comorbidities in addition to senescence, the relative risk of death (estimated by the CCI, CACI, FCI) for this group was categorized as moderate.

It is known that an increased number of professionals attending a single patient predisposes iatrogenic outcomes ${ }^{13}$. However, there was a relatively low average of prescribing physicians per elderly individual in this sample. In contrast, we found a high rate of polypharmacy, particularly of drugs acting on the cardiovascular system. Among these, there was a predominance of drugs for the treatment and prevention of atherothrombotic events in the elderly. In line with these findings, Brasil has an estimated prevalence between $5 \%$ and $8 \%$ of coronary disease in the adult population, which makes it the main cause of mortality. For this reason, actions for the progressive reduction of the mortality rate from cardiovascular diseases are being implemented since, in most cases, these are measures liable to interventions ${ }^{11}$.

It is important to highlight in this group that $74.2 \%$ of the elderly individuals made use of, at least, one MPI with an imminent risk of ADE-CC. This is a particular concern for researchers, considering the clinical vulnerability of the group researched. Among the potential risks of ADE-CC of lower severity, systemic arterial hypertension was the most prevalent, whereas, among the ADE-CC of greater severity, heart failure/exacerbation was the main potential risk. These data indicate that a portion of the diseases related to the circulatory system may be influenced by medication. However, this has been little explored by researchers and neglected by professionals in clinical practice.

Brazilian studies have great variability in the prevalence of PIM consumption ${ }^{14}$. However, it should be considered that this wide variation in prevalence is justified in detriment of two major aspects: (i) sample size and (ii) the difference in the application of separate instruments for screening PIM, thus, hindering further analyses.

Among the factors associated with the consumption of PIM with a potential risk of ADE-CC found here, the presence of variables related to clinical conditions were the main ones associated with this outcome, such as: the presence of comorbidities, diseases of the circulatory system, score in addition to the risks of morbidity and mortality, and the use of polypharmacy. It is important to highlight that since this is a group of individuals undergoing an active process of aging, whose changes facilitate the increasing rates of chronic conditions, i.e., three or more comorbidities, particularly cardiovascular conditions, this led to the high consumption of medicines, predisposing iatrogenic outcomes, as evidenced. Studies have shown a significant and increased risk for the consumption of PIM in elderly patients with comorbidities, particularly cardiovascular diseases and in the presence of polypharmacy, in line with the findings of this study ${ }^{13,15-17}$.

We should warn that, although these findings are unprecedented, they corroborate their consolidation, in addition to acting as indicators for the pharmacological management of risk groups. These findings corroborate the development of preventive measures targeted at the elderly in health care services, in order to avoid the inappropriate consumption of medicines, emergence of potential interactions and adverse events, increase in the number of hospital admissions, and even the prolongation of hospitalization $^{13.18}$.

It is interesting to highlight the occurrence of an unprecedented finding: the presence of neurological symptoms as a $63 \%$ protective factor to ADE-CC. The presence of symptoms such as headache, insomnia, amnesia, and mental confusion had an unexpected weigh on this analysis and needs to be further investigated in this scenario.

\section{Limitations}

This study has some limitations. The results do not allow for generalization to all elderly individuals because the study included only individuals undergoing clinical follow-up in teaching outpatient clinic of a secondary hospital located in Carapicuíba, SP, Brasil. The analysis of undesirable outcomes, such as functional deterioration, hospitalization, admission in emergency care services, institutionalization, and death was not assessed given the scope of the analysis and the nature of the study design.

It is important to highlight that, due to the limitations of the clinic's digital system, the absolute outlining of prior hospitalizations per elderly individual was impaired. However, it is estimated that nearly two-thirds of the elderly individuals undergoing follow-up in this outpatient clinic of medical specialties have already had at least one hospitalization in this service. 


\section{CONCLUSION}

The vast majority of the elderly patients included in this study were part of a group of imminent risk for ADE-CC. It should be noted that, in addition to the considerable risk of morbidity and mortality in this group, in most cases, the therapeutic care provided focused on the treatment and prevention of atherothrombotic events.
The screening of risk factors showed that having three or more comorbidities, diseases of the circulatory system, making use of polypharmacy, and having a moderate score in indexes of morbidity and mortality were important factors associated with an increased odds ratio for the use of PIM with a risk of ADE-CC. It is also worth mentioning that the presence of neurological symptoms was a protective factor for this outcome.

\section{RESUMO}

OBJETIVO: Identificar o uso de Medicamentos Potencialmente Inapropriados (MPI) com risco iminente de EAM cardiovascular e cerebrovascular (EAM-CC), além dos fatores associados a um grupo de idosos em vigência terapêutica de um serviço público brasileiro.

MÉTODOS: Estudo seccional e retrospectivo realizado em um serviço de nível secundário localizado em Carapicuíba, SP, Brasil. Incluíram-se, apenas, idosos (idade $\geq 60$ anos) que foram tratados em um departamento de atendimento ambulatorial. O uso de MPI com risco iminente de EAM-CC foi definido empregando a lista PIM-CCVAEs. Nesta pesquisa, apropriou-se da estatística descritiva e de regressão logística para identificação e rastreio de possíveis preditores de uso de MPI. Todas as análises estatísticas foram realizadas usando o software Stata version 15.1 (Stata Corporation).

RESULTADOS: Incluíram-se, na casuística, 233 idosos, com média de idade igual a 74,9 (ะ9,4) anos. Destes, 74,2\% faziam uso de pelo menos um MPI com risco de EAM-CC, atingindo uma média de consumo diário igual a 1,3 ( \pm 1) MPI/idoso. Verificou-se que a presença de comorbidades, doenças do aparelho circulatório, polifarmácia e score baixo a moderado em índices de morbimortalidade foram importantes fatores associados ao aumento da razão de chances para o consumo de MPI com risco de EAM-CC. Ressalta-se ainda que a presença de sintomas neurológicos mostrou-se como fator protetor para este desfecho.

CONCLUSÃO: Dada a gravidade clínica e o risco iminente de EAM-CC do grupo pesquisado, medidas de prevenção devem ser instituídas com o intuito de minimizar os problemas de saúde relacionados à medicação na rede pública.

PALAVRAS-CHAVE: Idoso. Resultado do tratamento. Doença iatrogênica. Lista de medicamentos potencialmente inapropriados. Efeitos colaterais e reações adversas relacionados a medicamentos. Sistema cardiovascular.

\section{REFERENCES}

1. World Health Organization. Cardiovascular diseases (CVDs). Geneva: World Health Organization; 2017. [cited 2019 Ago 30]. Available from: https://www. who.int/news-room/fact-sheets/detail/cardiovascular-diseases-(cvds)\#targetText=Key\%20facts,than\%20from\%20any\%20other\%20cause.\&targetText=Out\%20of\%20the\%2017\%20million,37\%25\%20are\%20caused\%20 by\%20CVDs

2. Storms H, Marquet K, Aertgeerts B, Claes N. Prevalence of inappropriate medication use in residential long-term care facilities for the elderly: a systematic review. Eur J Gen Pract. 2017;23(1):69-77.

3. Oliveira HSB, Corradi MLG. Pharmacological aspects of elderly: an integrative literature review. Rev Med (São Paulo). 2018;97(2):165-76.

4. Schmiedl S, Rottenkolber M, Szymanski |, Drewelow B, Siegmund W, Hippius M, et al; German Net of Regional Pharmacovigilance Centers (NRPC). Preventable ADRs leading to hospitalization: results of a long-term prospective safety study with 6,427 ADR cases focusing on elderly patients. Expert Opin Drug Saf. 2018;17(2):125-37.

5. Aguiar JP, Heitor Costa L, Alves da Costa F, Leufkens HG, Martins AP. Identification of potentially inappropriate medications with risk of major adverse cardiac and cerebrovascular events among elderly patients in ambulatory setting and long-term care facilities. Clin Interv Aging. 2019;14:535-47.

6. Aguiar JP, Brito AM, Martins AP, Leufkens HGM, Alves da Costa F. Potentially inappropriate medications with risk of cardiovascular adverse events in the elderly: a systematic review of tools addressing inappropriate prescribing. J Clin Pharm Ther. 2019;44(3):349-360.

7. MdCalc. Charlson comorbidity index (CCl): predicts 10 -year survival in patients with multiple comorbidities. 2005. [cited 2019 Mar 20]. Available from: https://www.mdcalc.com/charlson-comorbidity-index-cci

8. Medical Online Calculators Library (pmidCALC). Charlson age-comorbidity index (CACI). 2019. [cited 2019 Mar 20]. Available from: http://www.pmidcalc.org/?sid=7722560\&newtest $=Y$

9. Groll DL, To T, Bombardier C, Wright JG. The development of a comorbidity index with physical function as the outcome. I Clin Epidemiol. 2005;58(6):595-602.

10. World Health Organization (WHO) Collaborating Centre for Drug Statistics Methodology. Anatomical Therapeutic Chemical/defined daily doses (DDDs) Index 2019. [cited 2019 Mar 20]. Available from: https://www. whocc.no/atc_ddd_index/

11. Silveira EL, Cunha LM, Pantoja MS, Lima AVM, Cunha ANA. Prevalência e distribuição de fatores de risco cardiovascular em portadores de doença arterial coronariana no Norte do Brasil. Rev Fac Ciênc Méd Sorocaba. 2018:20(3):167-73.

12. Ruan $Y$, Guo $Y$, Zheng $Y$, Huang Z, Sun S, Kowal P, et al. Cardiovascular disease (CVD) and associated risk factors among older adults in six low-and middle-income countries: results from SAGE Wave 1. BMC Public Health. 2018;18(1):778.

13. Alhawassi TM, Alatawi W, Alwhaibi M. Prevalence of potentially inappropriate medications use among older adults and risk factors using the 2015 American Geriatrics Society Beers criteria. BMC Geriatr. 2019;19(1):154.

14. Oliveira HSB, Manso MEG. The iatrogenic triad in a group of elderly women contracted to a health plan. Rev Bras Geriatr Gerontol. 2019;22(1):e180188.

15. Vieira de Lima TJ, Garbin CA, Garbin AJ, Sumida DH, Saliba O. Potentially inappropriate medications used by the elderly: prevalence and risk factors in Brazilian care homes. BMC Geriatr. 2013;13:52.

16. Hamano |, Tokuda Y. Inappropriate prescribing among elderly home care patients in Japan: prevalence and risk factors. J Prim Care Community Health. 2014;5(2):90-6.

17. Wawruch M, Fialova D, Zikavska M, Wsolova L, Jezova D, Kuzelova M, et al. Factors influencing the use of potentially inappropriate medication in older patients in Slovakia. J Clin Pharm Ther. 2008;33(4):381-92.

18. Spinewine A, Fialová D, Bryrne S. The role of pharmacist in optimizing pharmacotherapy in older people. Drugs Aging. 2012;29(6):495-510. 